\title{
Seismic Behavior of Persian Brick Arches
}

\author{
Majid Pouraminian ${ }^{1 *}$, Arjang Sadeghi ${ }^{2}$ and Somayyeh Pourbakhshiyan ${ }^{3}$ \\ 1,30partment of Civil Engineering, Ramsar Branch, Islamic Azad University, Ramsar, Iran; \\ mpouraminian@iauramsar.ac.ir, spourbakhshian@iauramsar.ac.ir \\ 2Department of Civil Engineering, Azarbaijan Shahid Madani University, Tabriz, Iran; a.sadegh@azaruniv.edu
}

\begin{abstract}
The application of arch structural form in Iran goes back to as far as thousands of years ago. Arch is a fundamental component of Iranian architecture. Other structural systems such as vaults and domes are indeed derived from arch. In the present study, the stability of various Iranian arches with regards to weight, surcharge and earthquake has been analyzed. The most applicable Iranian arches analyzed in this study include circular arches, parabolic-shaped arches, onion-shaped arches, four-centered pointed arches, obtuse angel arches and basket-handle arches which have been transferred into ANSYS software medium following the geometrical modeling in AutoCAD software. The static analysis, modal analysis and linear and non-linear dynamic analysis have been carried out on limited components model. Having compared the results of the analyses, it was recognized that for the same span and thickness in various Iranian arches analyzed in the present study, the parabolic-shaped arch has a better bearing with respect to gravity and lateral loads, and the onion-shaped arch is void of adequate resistance under its own weight and the gravity surcharge. The static stability of the arches under the gravity load from low to high is respectively as follows: the Semi-elliptical arch, the parabolic-shaped arch, basket-handle arch, circular arch and four-centered pointed arch. Also the seismic stability of the arches is obtained from high to low as follows: the parabolic-shaped arch, the basket handle arch, the four-centered pointed arch, the Semi-elliptical arch and the circular arch. The location of cracks' threshold in the arches damaged by seismic loading is in the internal face of the arch. Also, the time and ways of arch collapse have been obtained which will be discussed in the text of the study.
\end{abstract}

Keywords: FE Modeling, Cracking Pattern, Non-linear analysis, Persian Arches, Seismic Behavior, Seismic Vulnerability

\section{Introduction}

The oldest arch existing in Iran belongs to about 2000 years B.C which has been applied in Chagh-Zanbil. Arches can be defined as curved lines whose spans are usually bigger than their rises. Overall, arches are classified to three groups":

1 Circular arches and similar to that

2 Obtuse angle arches

3 Decorative arches

According to Figure 1, the $\mathrm{AB}$ part is referred to as the vault's key. The lowest part of the vault i.e. $\mathrm{CD}$ and $\mathrm{EF}$ are the base of the vault and the proportion of the base to the vault's key is at least one. The differences of height between the vault's key and the base, is the vault's rise (AM) and EC the span length. In this study, the span applied in all arches is 8 meters, $\mathrm{CD}=60 \mathrm{~cm}$ and $\mathrm{AB}=40 \mathrm{~cm}$. In arch modeling, the tolerance increases because the thickness decreases from base to top. We should remember that in modeled arch, the thickness decrease from base (FE) to top (AB) linearly. Also, arch thickness in direction of length axis is $60 \mathrm{~cm}$. The motion of support nodes is zero, and dynamic force has no effect on them. Also, brick masonry is made by brick and mortar as homogenous material show in the left column of Table 1. The efficient factors in inelastic nonlinear analysis show in the 2 right columns of Table 1. The increase of thickness from the vault's key to the base of the vault is considered to be linear. The arches analyzed in this study include: semi-circular, basket handle, parabolic, four centered, semi-elliptical and onion shape which have

${ }^{*}$ Author for correspondence 
Table 1. Physical specifications, Yield criterion and failure surface setting used in the finite element modeling ${ }^{3}$

\begin{tabular}{clc}
\hline The physical specifications of the materials & \multicolumn{1}{c}{ Willam and Warnke surface } & Yield Drucker-Prager criterion \\
\hline$E=7 \times 10^{9} \mathrm{~Pa}$ & $\beta \mathrm{t}=0.1$ & $\mathrm{C}=100000 \mathrm{~Pa}$ \\
& Shear transfer coefficients for an open crack & the cohesion value \\
& $\beta c=0.9$ & $\varphi=20^{\circ}$ \\
$f_{t}=2 \times 10^{5} \mathrm{~Pa}$ & Shear transfer coefficients for a closed crack & the angle of internal friction \\
& $\sigma_{t}=0.2 \mathrm{Mpa}$ & $\eta=15^{\circ}$ \\
& Uniaxial tensile cracking stress & the dilatancy angle \\
& $\sigma_{c}=2.5 \mathrm{Mpa}$ & - \\
& Uniaxial crushing stress & \\
$\varepsilon_{c}=0.002, v=0.2$ & &
\end{tabular}

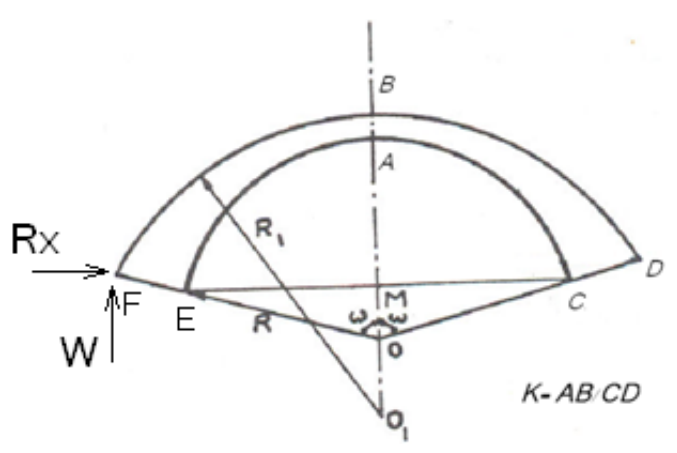

Figure 1. The characteristis of arch's geometry.

been shown in Figure 2. The rise and weight of the above mentioned arches are presented in Table 2 .

\section{The Static Analysis under the Arch's Weight and the Over Load}

Finite element modeling of the arches is created by using a Solid 45, 8-node element and the arch has been modeled in the base of the vault in the form of fixed base. A linear elastic behavior has been considered for the elements Most arches are applied as bearing elements in the structure and they must tolerate the over load gravity in addition to their weight. In fact arches play the role of girder in today's structures. The share of the arch from the gravity over load gravity on the arch is assumed to be $60 \mathrm{KN}$. This amount has been obtained as a result of assuming the loading width to be 6 to 10 times of the arch's width and has been selected at a low level. The reason for this fact is that unlike the modern structures, in the masonry and historical structures the gravity load causes the increase of the lateral bearing capacity. This load has been gravity considering the geometry of the arch and in the form of exertion. In Table 3, the results of static analysis and the values of maximum tension stress and

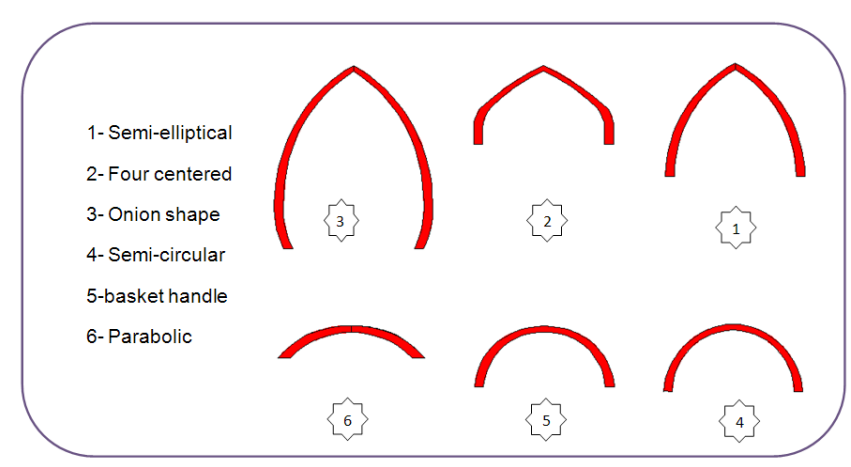

Figure 2. The characteristics of the modeled arch's geometry applied in the study.

compression created in each arch have been presented. Maximum deformation shape can be also seen in Table 3. In arches having key vaults the maximum rise occurs in a place lower than the key and for other arches it occurs on the symmetry axis of the arch. Allowable stresses have been shown in Table 1 Arches' deformation, with the exception of the onion shape arch, is in the limit of allowable values. (Allowable strain of the masonry materials is assumed to be $\varepsilon_{c}=0.002$ ). For the onion shape arch the tension values are beyond the allowable tensions of the materials and therefore this arch with its assumed thickness does not have the necessary strength for the over load and consequently is instable against seismic loading. Among the other 5 arches the existing stress strength is less than the allowable values however the elastic tension of the circular and four centered arches is more than its allowable values and as a result in places with elastic tensions higher than the allowable values, material cracking might occur. For the parabolic and semi-elliptical arches all the results display a low level of maximum rise, elastic tension and maximum compression and the probability of cracking and crushing is very low, therefore the semi-elliptical arch and parabolic arches have a suitable 
Table 2. The specifications of the arches used in the study

\begin{tabular}{|c|c|c|c|c|c|}
\hline The Arch & Rise $(\mathrm{m})$ & Span $(\mathrm{m})$ & The proportion of the rise to the height & Weight $(\mathrm{KN})$ & The arch's internal radius \\
\hline Semi-elliptical & 6.90 & 8 & 0.86 & 61.58 & $r_{1}=8$ \\
\hline Four centered & 3.7 & 8 & 0.46 & 45.70 & $\begin{array}{l}r_{1}=2 \\
r_{2}=10.40\end{array}$ \\
\hline Onion shape & 11.90 & 8 & 1.49 & 96.39 & $\begin{array}{l}r_{1}=5.77 \\
r_{2}=9.55\end{array}$ \\
\hline Semi-circular & 4 & 8 & 0.50 & 42.07 & $r_{1}=4$ \\
\hline basket handle & 3.50 & 8 & 0.43 & 43.90 & $\begin{array}{l}r_{1}=3.78 \\
r_{2}=4\end{array}$ \\
\hline Parabolic & 2.06 & 8 & 0.26 & 37.16 & $r_{1}=5.70$ \\
\hline
\end{tabular}

Table 3. The results of the analysis under the weight and the over load of the arch

\begin{tabular}{|c|c|c|c|c|}
\hline \multirow{2}{*}{$\begin{array}{l}\text { Various arches with } \\
8 \mathrm{~m} \text { span }\end{array}$} & \multirow{2}{*}{$\begin{array}{l}\text { Maximum } \\
\text { displacement }\end{array}$} & \multirow[t]{2}{*}{ Arch deformation shape } & \multicolumn{2}{|c|}{ Location and amount of maximum tension (Mpa) } \\
\hline & & & compressive & tensile \\
\hline Semi-circular & 0.69 & & $\begin{array}{l}0.64 \text { external face of } \\
\text { the fixed base }\end{array}$ & $\begin{array}{l}0.26 \text { internal face of } \\
\text { the fixed base }\end{array}$ \\
\hline basket handle & 0.67 & & $\begin{array}{l}0.53 \text { external face of } \\
\text { the fixed base }\end{array}$ & $\begin{array}{l}0.19 \text { internal face of } \\
\text { the arch's key }\end{array}$ \\
\hline Parabolic & 0.55 & & $\begin{array}{l}0.54 \text { external face of } \\
\text { the arch's key }\end{array}$ & $\begin{array}{l}0.09 \text { internal face of } \\
\text { the fixed base }\end{array}$ \\
\hline Four centered & 0.6 & & $\begin{array}{l}0.69 \text { external face of } \\
\text { the fixed base }\end{array}$ & $\begin{array}{l}0.34 \text { internal face of } \\
\text { the fixed base }\end{array}$ \\
\hline Semi-elliptical & 0.34 & & $\begin{array}{l}0.47 \text { external face of } \\
\text { the fixed base }\end{array}$ & $\begin{array}{l}0.07 \text { external face of } \\
\text { the arch's key }\end{array}$ \\
\hline Onion shape & 5.4 & & $\begin{array}{l}20 \text { external face of } \\
\text { the arch's key }\end{array}$ & $\begin{array}{l}5.50 \text { internal face of } \\
\text { the fixed base }\end{array}$ \\
\hline
\end{tabular}


exertion bearing and the four centered as well as onion shape arches are not suitable. The force transmission in all section of the parabolic arch, especially in the base of the vault, is mainly in the form of compression and the elastic tensions are condonable. Considering the Table 3, we can explain the stability of the arches under the exertion loading from high to low as follows: The semi-elliptical arch, the parabolic, the basket handle arch, the circular arch, the four centered arch and the onion shape arch.

Generally, under the gravity loads the increase in the arch's rise leads to an increase in the vertical elements of the base of the vault and a decrease in the horizontal thrust of the arch force the values of which have been shown in Table $4^{2}$. From the F value shown in Table 4, we can obtain the amount and the resultant angle of the gravity forces to each base of the vault. The interpretation of $\mathrm{F}$ amount for the parabolic arch $(\mathrm{F}=1.04)$ is indicative of the fact that the resultant force angle of the base of the arch (in this study the base of the arch angle with the horizontal axis equals to 46 degrees), is parallel to the tangent line on the arch in the base of the vault, which causes the elastic tensions and compressions in this critical region to be steady and the bearing capacity to be used effectively.

\section{Modal Analysis}

Using modal analysis in the major direction axes $\mathrm{X}, \mathrm{Z}$, dominant modes were separately obtained for which the form, period and modal participation mass ratios have been shown in Table 5. The damping ratio is assumed to be 0.07 . In unreinforced masonry structures the damping ratio is more than the modern structures. The reason is the existence of many hair cracks in these structures ${ }^{3}$. The basis for selecting the principal modes is the highest modal participation mass ratio, and in modes in which these ratios are closer, all modes are selected with a high modal participation mass ratio. By comparing the sequence time of the main period of the various arches in Table 5 , it can be distinguished that for the arches with height proportion to the same span, this amount is higher for the key vaults than the circular and semi-elliptical arches. Also, longer sequence time of the onion shape arches indicates their less lateral stiffness and higher mass. From among the various arches the longest and the shortest sequence time respectively belongs to onion shape and parabolic arches that indicate the amount of the high stiffness of the parabolic arch.

\section{Linear Dynamic Analysis}

We used a linear analysis. The mechanical features of the materials are the same as the linear features of the materials used in the static analysis. In Table 6 the characteristics of the accelerograms used in this study have been presented. These accelerograms are the horizontal parameters. The response of the arch to the Kobe accelerogram's loading was more than the other accelerograms, therefore only the response related to those results are given here. In the last part of the present study, in Table 7, as a mere sample some responses of the arch under Manjil and Tabas accelerogram's loading (ineffective accelerograms) have been shown. As it can be seen, the responses under Kobe accelerogram's loading for the same arch points have more responses. The results of the maximum tensions and their locations have been shown in Table 8. The proportion of the vault's base thrust of the arch to the vertical reaction of the vault's base is a significant parameter in the analysis of the arches' structure. By comparing the results of Tables 4 and 8 , it can be observed that with the increase in the arch's height, the horizontal force decreases and the arch becomes more stable and heavier against exertion loading.

With the exception of the onion shape arch which could not tolerate the exertion loading, the other arches have less compression stress than the allowable values and with regards to elastic tensions only in the parabolic arch the tension values are less than the allowable values. The lateral bearing of the parabolic arch is very suitable and the elastic and compression tensions existing in it are

Table 4. The results of arches analysis under weight and the (gravity) over load

\begin{tabular}{lcccccc}
\hline Various arches with 8 m span & Semi-elliptical & Four centered & Parabolic & basket handle & Semi-circular & Onion shape \\
\hline Rise (m) & 6.90 & 3.70 & 2.06 & 3.50 & 4 & 11.90 \\
$\begin{array}{l}\text { (RX) the thrust of the arch force } \\
\text { in the base of the vault (KN) }\end{array}$ & 13.1 & 18.50 & 44.5 & 22.10 & 18.60 & 9.98 \\
$\begin{array}{l}\text { (W) the vertical force in the base } \\
\text { of the vault (KN) }\end{array}$ & 55.50 & 47.10 & 42.47 & 46.30 & 47.80 & 72.60 \\
F=Rx / W & 0.24 & 0.39 & 1.04 & 0.48 & 0.39 & 0.14 \\
\hline
\end{tabular}


Table 5. The results of modal analysis

\begin{tabular}{|c|c|c|c|c|}
\hline $\begin{array}{l}\text { Various arches with } \\
8 \mathrm{~m} \text { span }\end{array}$ & The arch rise & $\begin{array}{l}\text { The form of dominant } \\
\text { vertical mode }\end{array}$ & $\begin{array}{l}\text { The form of dominant } \\
\text { horizontal mode }\end{array}$ & $\begin{array}{c}\text { Period (s) TDIR } \\
\text { mass Participation } \\
\text { Ratio (P.F) } \\
\end{array}$ \\
\hline \multirow[t]{2}{*}{ Semi-circular } & 4 & & & $\begin{aligned} \mathrm{Tx} 1 & =0.083 \\
\mathrm{P} . \mathrm{F} & =54.79\end{aligned}$ \\
\hline & & & & $\begin{aligned} \mathrm{Tz} 4 & =0.016 \\
\mathrm{P} . \mathrm{F} & =44.26\end{aligned}$ \\
\hline \multirow[t]{2}{*}{ basket handle } & 3.50 & & & $\begin{aligned} \mathrm{Tx} 1 & =0.073 \\
\mathrm{P} . \mathrm{F} & =50.6\end{aligned}$ \\
\hline & & th Mode & & $\begin{aligned} \mathrm{Tz} 4 & =0.015 \\
\mathrm{P} . \mathrm{F} & =43.1\end{aligned}$ \\
\hline \multirow[t]{3}{*}{ Parabolic } & 2.06 & & & $\begin{aligned} \mathrm{Tx} 1 & =0.035 \\
\text { P.F } & =33.2\end{aligned}$ \\
\hline & & & & $\begin{aligned} \mathrm{Tx} 4 & =0.011 \\
\mathrm{P} . \mathrm{F} & =33.3\end{aligned}$ \\
\hline & & & & $\begin{aligned} \mathrm{Tz} 2 & =0.026 \\
\mathrm{P} . \mathrm{F} & =36.14\end{aligned}$ \\
\hline \multirow[t]{2}{*}{ Four centered } & 3.70 & & & $\begin{aligned} \mathrm{Tx} 1 & =0.089 \\
\mathrm{P} . \mathrm{F} & =50.9\end{aligned}$ \\
\hline & & & & $\begin{aligned} \mathrm{Tz} 4 & =0.027 \\
\mathrm{P} . \mathrm{F} & =40.9\end{aligned}$ \\
\hline \multirow[t]{2}{*}{ Semi-elliptical } & 6.90 & & & $\begin{aligned} \mathrm{Tx} 1 & =0.147 \\
\mathrm{P} . \mathrm{F} & =64.85\end{aligned}$ \\
\hline & & & & $\begin{aligned} \mathrm{Tz} 6 & =0.015 \\
\mathrm{P} . \mathrm{F} & =55.55\end{aligned}$ \\
\hline \multirow[t]{2}{*}{ Onion shape } & 11.90 & & & $\begin{aligned} \mathrm{Tx} 1 & =0.407 \\
\text { P.F } & =83.89\end{aligned}$ \\
\hline & & Sevens Mode & & $\begin{aligned} \mathrm{Tz} 7 & =0.022 \\
\mathrm{P} . \mathrm{F} & =65.87\end{aligned}$ \\
\hline
\end{tabular}

Table 6. The characteristics of the accelerograms used in the study

\begin{tabular}{lccl}
\hline $\begin{array}{l}\text { The location of the earthquake } \\
\text { (duration time) }\end{array}$ & PGA (cm/s2) & PGA (g) & The results \\
\hline Kobe (30s) & 818 & 0.834 & The text of the study \\
Tabas (30s) & 816 & 0.832 & Table 7 \\
Manjil (30s) & 504 & 0.514 & Table 7 \\
\hline
\end{tabular}


Table 7. A number of results from non-linear dynamic analysis under other earthquake horizontal accelerograms

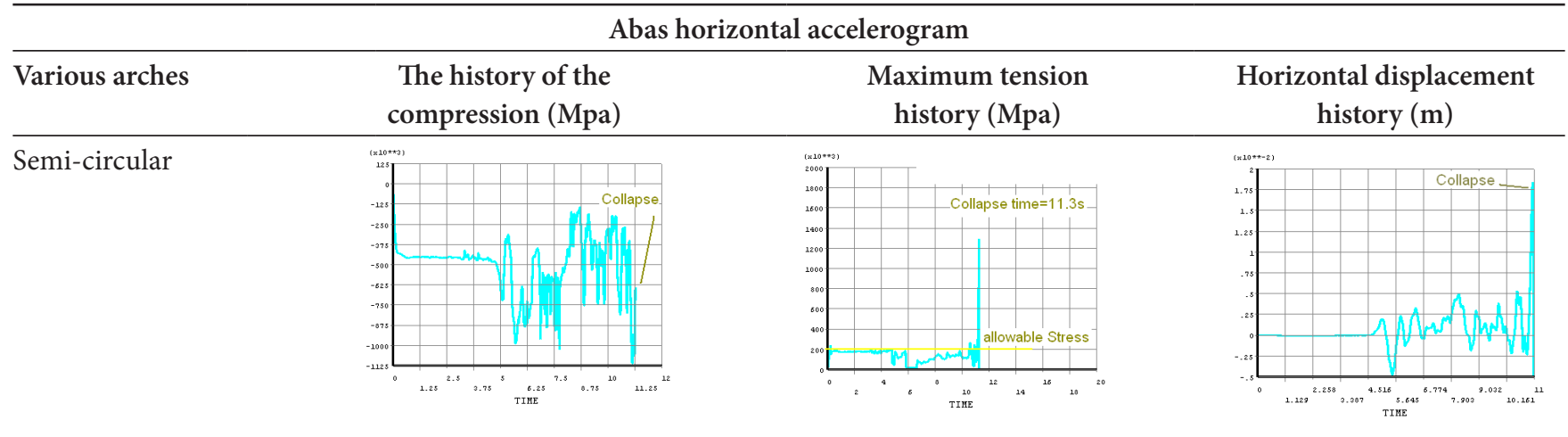

Parabolic (without collapse)

location The arch fixed base external face

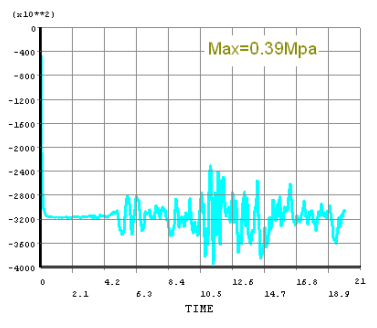

location The arch fixed base internal face
Four centered

Semi-elliptical (without collapse)

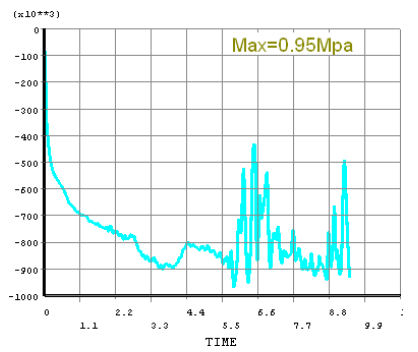

location The arch fixed base external face

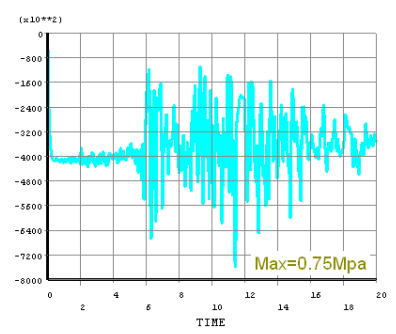

location The external face of the fixed end of the arch

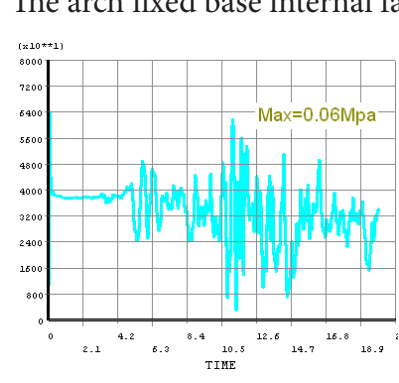

The arch fixed base internal face
The arch middle internal face

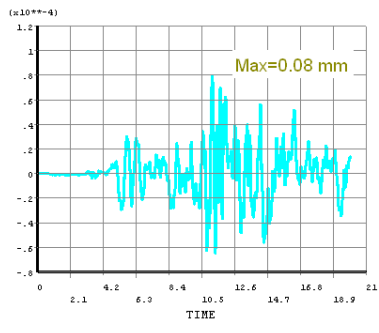

The arch middle internal face

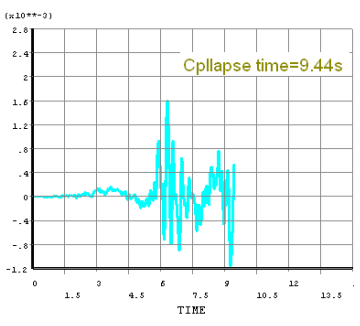

The arch middle internal face

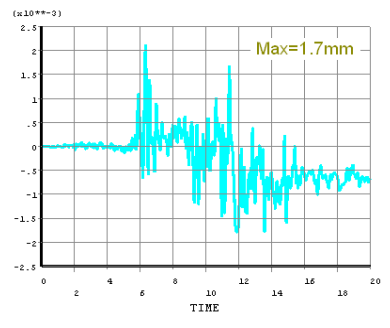

The internal face of the middle part of the arch less than the allowable values which have been shown in Table 8. In the parabolic arch, as it has been previously noted, the capacity of the sectioned bearing is used efficiently. In the dynamic analysis stage due to the weak performance in the static analyses, the onion shape arch was put aside. The analysis of the results obtained from the arches' analysis indicates that the maximum tensions are created in the location of the fixed bases. This is in spite of the fact that the arches have bigger section and moment inertia. 
Table 8. The dynamic analysis under the horizontal accelerogram of Kobe earthquake

\begin{tabular}{|c|c|c|c|c|c|c|}
\hline $\begin{array}{l}\text { Various arches } \\
\text { with } 8 \mathrm{~m} \text { span }\end{array}$ & Arch rise $(\mathrm{m})$ & $\begin{array}{c}\text { Arches' base of the } \\
\text { vault thrust of the arch } \\
\text { RX (KN) }\end{array}$ & $\begin{array}{c}\text { Vertical force of } \\
\text { the arches' base } \\
\text { of the vault }\end{array}$ & $\mathrm{RX} / \mathrm{W}$ & $\begin{array}{l}\text { The amount and } \\
\text { situation of the } \\
\text { maximum elastic } \\
\text { tension (Mpa) }\end{array}$ & $\begin{array}{l}\text { The amount and } \\
\text { situation of the } \\
\text { maximum elastic } \\
\text { compression (Mpa) }\end{array}$ \\
\hline Semi-circular & 4 & 20.05 & 48.16 & 0.41 & $\begin{array}{l}1 \text { internal face of } \\
\text { the fixed base }\end{array}$ & $\begin{array}{l}1.35 \text { external face of } \\
\text { the fixed base }\end{array}$ \\
\hline basket handle & 3.50 & 22.08 & 46.30 & 0.48 & $\begin{array}{l}0.85 \text { internal face of } \\
\text { the fixed base }\end{array}$ & $\begin{array}{l}1.18 \text { external face of } \\
\text { the fixed base }\end{array}$ \\
\hline Parabolic & 2.06 & 44.51 & 42.47 & 1.05 & $\begin{array}{l}0.14 \text { internal face of } \\
\text { the fixed base }\end{array}$ & $\begin{array}{l}0.59 \text { internal face of } \\
\text { the fixed base }\end{array}$ \\
\hline Four centered & 3.70 & 17.86 & 46.54 & 0.38 & $\begin{array}{l}1.18 \text { internal face of } \\
\text { the fixed base }\end{array}$ & $\begin{array}{l}1.57 \text { external face of } \\
\text { the fixed base }\end{array}$ \\
\hline Semi-elliptical & 6.90 & 13.10 & 55.50 & 0.24 & $\begin{array}{l}1.46 \text { internal face of } \\
\text { the fixed base }\end{array}$ & $\begin{array}{l}1.95 \text { external face of } \\
\text { the fixed base }\end{array}$ \\
\hline
\end{tabular}

In Table 9, the history of the displacement, principal elastic tension and principal compression stress in the critical locations have been shown. From Tables 3 and 9 it can be observed that the maximum displacement of the parabolic arch under the exertion load is approximately 8 times more than its displacement under Kobe earthquake load which itself indicates the high stiffness of the arch in the direction of the horizontal axis.

\section{Non-linear Dynamic Analysis}

The dynamic analysis of time history is a meticulous method for determining the response of the structure momentarily against the gravity earthquake acceleration to its bases provided that the defined behavior includes both linear and non-linear scopes. In such an analysis the response of the structure is a function of time. If the rupture criteria are well introduced in the definition of the characteristics of the structures' material and the existing values of its tension or strain exceed its allowable values, then rupture will occur. In this situation the nature of the independent time parameter becomes more important than the situation in which the proportion of the existing stress to the allowable stress value is less than one. In the non-linear dynamic analysis the collapse time of the arches is shown in Table 10. For the non-linear dynamic analysis, arches have been modeled using 3-D element Solid 65. in the existing analyses, arches in the non-linear scope have been considered to be elastic. The model of cracks considered by this element is the same as the one used in arch meshing the distributed macro model as well as the failure criterion used in William-Warnke criteria. The necessary parameters in William-Warnke and Drucker-Prager criteria have been considered in the nonlinear behavior modeling as shown in 1. (Pouraminian et al. 2008). The stress-strain curve is in the form of elasticperfect plastic and the strain hardening has been ignored. From among the 5 arches which have suitable exertion bearing, the parabolic arch could effectively tolerate Kobe earthquake seismic loading, which had the biggest effect on the five arches, and the other 4 arches have undergone collapse in various times as shown in Table 10. In all the cracked arches, the location of the cracks' starting point is in the internal face of the arch while in the circular and basket handle arches the location is in the vault's key and in four center and semi-elliptical arches the location is in the fixed base. Table 11 shows the displacement history and the principal compression in the critical points. According to Table 10, considering the collapse time of the arches we can assume the seismic stability of the arches respectively from highest to the lowest as follows: the parabolic arch, the basket handle arch, the four center arch, the semi-elliptical arch and the circular arch. These results can be observed through the behavior of the arches in other earthquakes such as Tabas and Manjil earthquakes.

\section{Conclusions}

For the same span and thickness in various Iranian arches discussed in the present study, the parabolic arch has a more suitable bearing with regards to the gravity and 
Table 9. The results of the linear dynamic analysis under Kobe earthquake's horizontal accelerogra

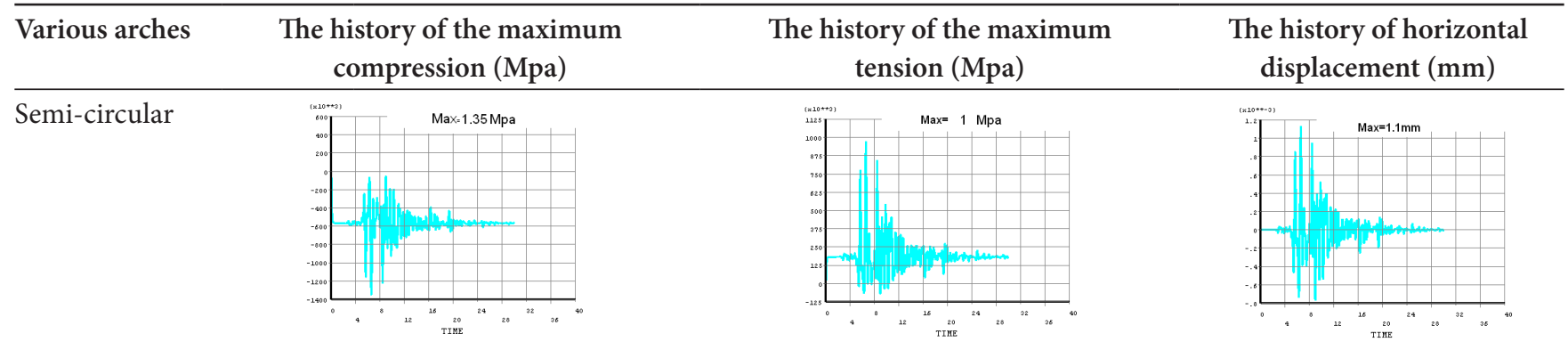

location The external face of the fixed end of the arch

basket handle

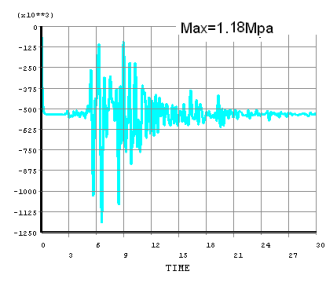

location The external face of the fixed end of the arch

Parabolic

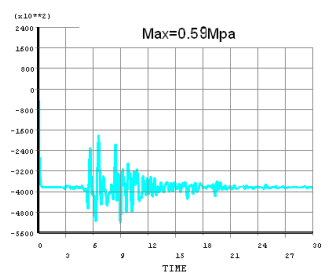

location The internal face of the fixed base of the arch

Four centered

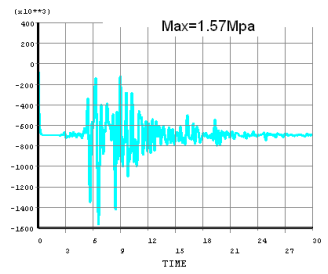

location The external face of the fixed end of the arch

Semi-elliptical

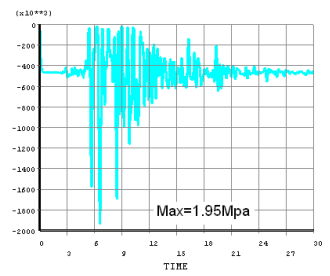

location The external face of the fixed end of the arch
The internal face of the fixed base of the arch

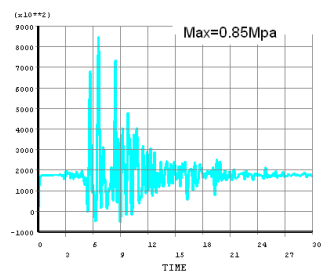

The internal face of the fixed base of the arch

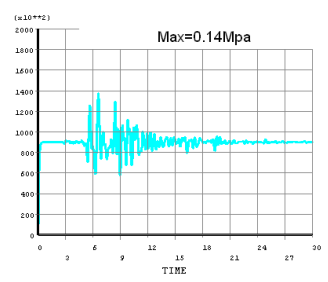

The internal face of the fixed base of the arch

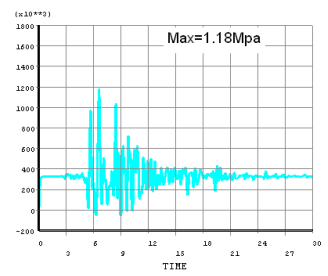

The internal face of the fixed base of the arch

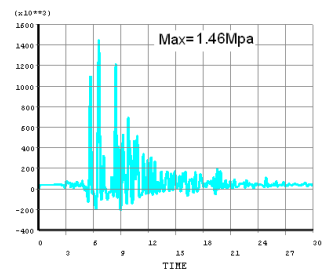

The internal face of the fixed base of the arch
The internal face of the middle part of the arch

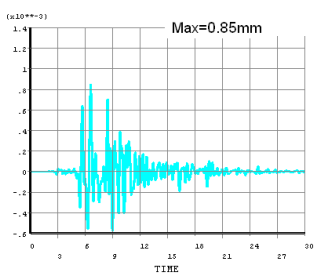

The internal face of the middle part of the arch

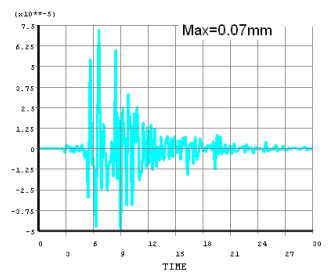

The internal face of the middle part of the arch

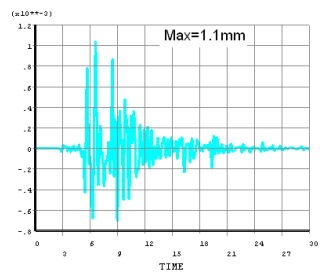

The internal face of the middle part of the arch

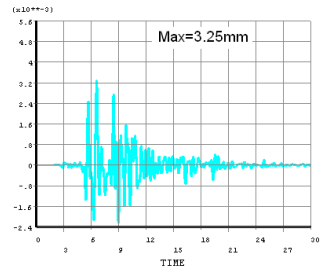

The internal face of the middle part of the arch 
Table 10. Non-linear dynamic analysis under Kobe earthquake horizontal accelerogram

\begin{tabular}{|c|c|c|c|c|}
\hline Various types of arches & The arch rise $(\mathrm{m})$ & The arch collapse time & $\begin{array}{l}\text { The situation of } \\
\text { the primary crack }\end{array}$ & Collapse form \\
\hline Semi-circular & 4 & 5.80 & $\begin{array}{l}\text { The internal face } \\
\text { of the middle part } \\
\text { of the arch }\end{array}$ & \\
\hline basket handle & 3.50 & 8.50 & $\begin{array}{l}\text { The internal face } \\
\text { of the middle part } \\
\text { of the arch }\end{array}$ & \\
\hline Parabolic & 2.05 & - & Without collapse & \\
\hline Four centered & 3.70 & 6.62 & $\begin{array}{l}\text { The internal face } \\
\text { of the fixed base of } \\
\text { the arch }\end{array}$ & \\
\hline Semi-elliptical & 6.90 & 6.22 & $\begin{array}{l}\text { The internal face } \\
\text { of the fixed base of } \\
\text { the arch }\end{array}$ & \\
\hline
\end{tabular}

lateral loads and the onion shape arch does not have the sufficient resistance under its own weight as well as the gravity over load. Generally, under the gravity loads, the increase in the arch rise causes a decrease in the arch's base thrust of the arch force and an increase in the vertical force of the arch's base. The resultant force of the parabolic arches' vault's base, is approximately parallel to the tangent line on the arch (46 degrees in the present study) in the vault's base and 45 degrees which causes the and compression stress in this region to be uniform and the bearing capacity to be used efficiently. The static stability of the arches under the gravity load from high to low is respectively as follows: the semi-elliptical arch, the parabolic arch, the basket handle arch, the circular arch and the four center arch. Also, the seismic stability of the arches from high to low is as follows: the parabolic arch, the basket handle arch, the four center arch, the semi-elliptical arch and the circular arch. The location of the cracks' starting point in the arches which undergo damages of quake loading is in the internal face of the arch. For the circular and basket handle arches the location of the cracks is in the internal face of the vault's key and in the four center as well as the semi-elliptical arches is in the fixed base internal face. 
Table 11. The results of non-linear dynamic analysis under Kobe earthquake horizontal accelerogram

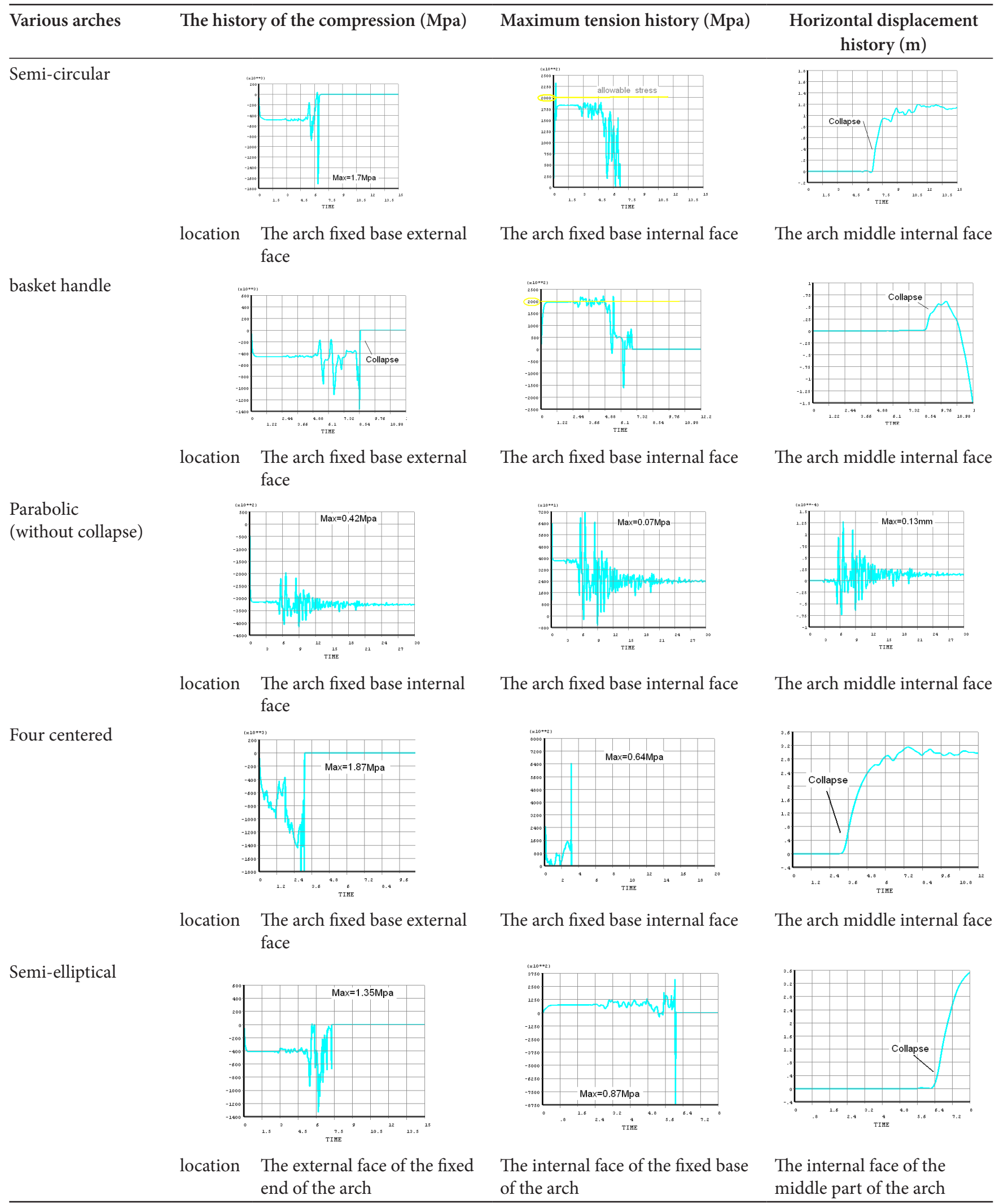




\section{References}

1. Zomorshidi H. Vault and arch in architecture. Keyhan Inst. Tehran, Iran; 1988.

2. Boothby EB. Manual for assessment of load-bearing URM buildings, Pennsylvania State University; 2006.
3. Hejazi M. Historical building of Iran, the Architecture and Structure, Southampton, UK; 1997.

4. Pouraminian M. Sadeghi A. Assessment seismic behavior of the historical structures (Case Study: Tabriz Citadel). 11th International Conference Oseismic Retrifitting, Tabriz, Iran; 2008 Oct. 